\title{
A TRADUÇÃo DE DUINESER ELEGIEN COMO ForMAÇÃo E MEMÓRIA LITERÁRIA NA AMAZÔNIA
}

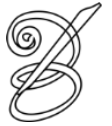 \\ Izabela Leal $^{1}$ \\ (Professora do Programa de Pós-Graduação em Letras da UFPA-Belém-Pará/Brasil) \\ izabelaleal@gmail.com \\ Jairo Vansiler ${ }^{2}$ \\ (Mestrando no Programa de Pós-graduação em Letras, com bolsa CAPES, UFPA-Belém-Pará/Brasil) \\ jjvansiler@gmail.com
}

Resumo: O objetivo deste trabalho é apresentar algumas considerações sobre a tradução de Duineser Elegien, de Rilke, realizada na Amazônia. Destaca-se, nesse contexto, a tradução do poeta Paulo Plínio Abreu, conjuntamente com o antropólogo alemão Peter Paul Hilbert, tendo como desdobramento as contribuições para a atualização da memória literária na Amazônia. A articulação teórica será feita a partir das considerações de Walter Benjamin e Antoine Berman sobre tradução, formação e crítica feita a partir da leitura dos Frühromantiker [Primeiros românticos alemães].

Palavras-chave: Tradução, memória, Rilke, Paulo Plínio Abreu, Amazônia.

Abstract: The aim of this paper is to present some considerations on the translation of Duineser Elegien, of Rilke, in the Amazon. We should emphasize, in this context, the translation of the poet Paulo Plinio Abreu, along with the German anthropologist Peter Paul Hilbert, resulting in contributions to the update of the literary memory on Amazon. The theoretical articulation will be from theoretical considerations of Walter Benjamin and Antoine Berman on translation, formation and critic made from the reading of Frühromantiker [Early German Romantics].

Keywords: Translation, Memory, Rilke, Paulo Plínio Abreu, Amazon.

\section{A MEMÓRIA DE UMA TRADUÇÃo}

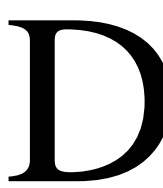
uas questões nos chamam a atenção na obra de Walter Benjamin para o desenvolvimento deste trabalho. A primeira é o seu conceito de "tradução como forma" e seu sentido ambivalente como Reflexionsmedium [médium-de-reflexão], que ele soube extrair dos Frühromantiker [Primeiros românticos alemães], como crítica de arte. A outra é o seu conceito de "história", envolvendo um intrincado jogo entre memória, esquecimento e atualização. Refletiremos sobre a imbricação desses conceitos, interligados por tênues passagens envolvendo materialismo histórico, alegorias místicas, poesia, filosofia, tradução e crítica.

O percurso da reflexão filosófica de Benjamin sobre a linguagem tem um marco em 1917 com Sobre a linguagem em geral e sobre a linguagem dos homens, em que o jovem crítico acredita no potencial da linguagem como uma espécie de incompletude do dizer 
autêntico através de um uso instrumental da língua. "A linguagem não oferece jamais meros signos", afirma Benjamin (2011, p. 63) se posicionando claramente diante desse tipo de uso, em que o modo de apresentação seria essencial, em detrimento do modo de representação, ou seja, o motivo da sua preocupação central seria a Form [forma] e não o Inhalt [conteúdo] da língua. Esse caminho encontrou seu pleno desenvolvimento acadêmico em 1919 com a sua tese de doutorado, intitulada $O$ conceito de crítica de arte no romantismo alemão. Na obra Die Aufbabe des Übersetzers, de 1923, Walter Benjamin radicaliza sua preocupação com a forma da linguagem ao dizer: "A tradução é uma forma. Para compreendê-la como tal, é preciso retornar ao original. Pois nele reside a lei dessa forma, enquanto encerrada em sua traduzibilidade" (BENJAMIN, 2011, p. 101).

Com efeito, percebemos em Benjamin uma leitura do pensamento dos primeiros românticos alemães, expresso na revista Athenäum (1798-1800). O fio condutor que o vincula ao conceito fundante destes, o Reflexionsmedium, caracteriza o exercício da crítica como um eterno vir-a-ser da Reflexão de si por meio da linguagem, numa rede de contraposições e incompletude. Vejamos o que diz Jeanne Marie Gagnebin:

\begin{abstract}
A dinâmica da autorreflexão imanente à obra (e agora que se entende melhor o valor argumentativo da insistência benjaminiana no conceito de "médium-de-reflexão") inscreve nela um inacabamento consecutivo; por ser obra de arte e obra do espírito, a obra quer ir além de si mesma, ela se abre às dimensões do infinito e do absoluto. Ora, a crítica é justamente, para os românticos de Iena, uma das respostas privilegiadas a esta exigência de autossuperação que caracteriza a verdadeira obra de arte, alojando na imanência da obra o movimento mesmo de sua transcendência (GAGNEBIN, 2007, p. 6).
\end{abstract}

Considerando a tradução como meio-de-reflexão crítica, a partir da passagem elucidativa de Gagnebin, percebemos o fundamento romântico para a construção benjaminiana de traduzibilidade [Übersetzbarkeit] da obra literária, contida em Die Aufgabe des Übersetzers, pois, em contato com o diferente (língua estrangeira), certas obras encontrariam o seu complemento enquanto afinidade intrínseca como autorreflexão:

\footnotetext{
A traduzibilidade é uma propriedade essencial de certas obras - o que não quer dizer que a tradução seja essencial para elas, mas que uma determinada significação contida nos originais se exprime em sua traduzibilidade. É mais que evidente que uma tradução, por melhor que seja, jamais poderá significar algo para o original. Entretanto, graças à traduzibilidade do original, a tradução se encontra com ele em íntima conexão (BENJAMIN, 2011, p. 104).
}

Dessa forma, acreditamos, Duineser Elegien é um modelo exemplar [Vorbilb, Urbild] de obra carregada de traduzibilidade, que em contato com a língua portuguesa, via tradução por um tradutor-poeta na Amazônia no meio do século XX, adquiriu o seu complemento 
formador, pois a sua característica de incompletude é a janela aberta para que essa obra seja sempre atualizada, em qualquer língua e em qualquer tempo. É a afinidade entre as línguas que garante a sua eterna atualização. Nas palavras de Benjamin: "Desse modo, a finalidade da tradução consiste, por último, em expressar o mais íntimo relacionamento das línguas entre si” (BENJAMIN, 2011, p. 106). O pensador alemão chamará de Überleben [“pervivência” ou "sobrevida"] a esta resultante característica da traduzibilidade. Portanto, no caso de Duineser Elegien, vemos realizada a tarefa do poeta-crítico Paulo Plínio Abreu como um tradutor de seu tempo.

Márcio Seligmann-Silva percebe que há na relação entre poesia e filosofia uma íntima relação desde a Grécia, cambiada pelos românticos alemães. Ele leu nos fragmentos da Athenäum: "O filósofo poetizante, o poeta filosofante é um profeta. $\mathrm{O}$ poema didático deveria ser profético e possui talento para assim tornar-se" (SCHLEGEL, 1967, II, p. 207 apud SELIGMANN-SILVA, 2005, p. 167) e ainda, "também a filosofia é resultado de duas forças conflitantes, a poesia e a prática. Onde ambas se interpenetram totalmente e se fundem numa, aí surge a filosofia" (SCHLEGEL, 1967, II, p. 216 apud SELIGMANN-SILVA, 2005). Dessa forma, a atividade de poetar pode ser vista como uma função crítica capaz de penetrar no sistema de linguagem, fazendo do tradutor um profeta que se antecipa ao discurso linear, questionando o seu modelo representacionista.

No seu último trabalho publicado em 1940, intitulado Sobre o conceito de História, Walter Benjamin questiona todo um modelo de história herdada de uma visão progressista e idealista do século XIX. Nessa obra, destacamos a tese 6, dentre as 17 , em que Walter Benjamin diz:

\begin{abstract}
Articular historicamente o passado não significa conhecê-lo "como ele de fato foi". Significa apropriar-se de uma reminiscência, tal como ela relampeja no momento de perigo. Cabe ao materialismo histórico fixar uma imagem do passado, como ela se apresenta, no momento de perigo, ao sujeito histórico, sem que ela tenha consciência disso. O perigo ameaça tanto a existência da tradição como os que a recebem. Para ambos, o perigo é o mesmo: entregar-se às classes dominantes, como seu instrumento. Em cada época, é preciso arrancar a tradição ao conformismo, que apodera-se dela. Pois o Messias não vem apenas como salvador; ele vem também como vencedor do Anticristo. O Dom de despertar no passado as centelhas da esperança é privilégio exclusivo do historiador convencido de que também os mortos não estarão em segurança se o inimigo vencer. Esse inimigo não tem cessado de vencer (BENJAMIN, 1986, p. 223).
\end{abstract}

Nessa passagem percebemos a clara diferenciação, digamos, epistemológica, dentro da articulação historiográfica desenvolvida por Benjamin. Com o materialismo histórico, o filósofo critica o historicismo, por ver neste um culto cego ao progresso, que não considera a 
memória como uma construção coletiva, capaz de desenvolver as capacidades criativas. E ainda, que a classe dominante se apodera da tradição, imobilizando-a em seu conformismo. Daí o papel do materialista histórico: despertar a centelha de esperança adormecida pela "segurança” dominadora. Diante disso, pensamos a partir de Seligmann-Silva (2010, p. 53) o procedimento historiográfico benjaminiano como uma "nova ética da memória", que, sem cair no tradicionalismo do conceito de ética, soube atualizá-lo de maneira sincronicamente impecável. Afinando um pouco mais, o ensaísta brasileiro continua,

\begin{abstract}
Benjamin foi um profundo teórico da memória, e sua prática de historiador e de crítico literário apresenta um modo de lidar com o seu objeto que podemos classificar como ético. O modo de trabalhar de Benjamin, sua ética de representação e da memória, seu compromisso com os excluídos da história, tudo isso aponta para o fato de que a sua obra ainda tem a contribuir para o século XXI. Talvez possamos falar desse pensador que a sua atualidade, paradoxalmente, não para de se evidenciar e confirmar com o decorrer dos anos (SELIGMANN-SILVA, 2010, p. 53).
\end{abstract}

Esses dois momentos da obra de Benjamin, no nosso entender, apontam para uma comunicação interna de seu pensamento como uma via de mão dupla, em que tanto a história quanto a obra literária precisam de atualização, ora como sobrevida, ora como Jetztzeit [tempo 34 do agora]. É nesse enquadramento que pensamos expor a tradução de Duineser Elegien como um fenômeno memorável, de uma história ainda hoje não contada, muito menos escrita: a história dessa tradução formadora de uma fecunda geração de intelectuais brasileiros, o Grupo dos Novos.

A partir de então nos reportaremos aos documentos levantados nas folhas do jornal paraense A Folha do Norte $^{3}$ da década de 1940, especialmente o seu encarte dominical chamado "Suplemento Arte-literatura", 4 para atestarmos que na Amazônia brasileira dessa época existiu uma discussão acalorada em torno da modernidade. Discussão esta que buscava atualizar a literatura paraense que se encontrava obsoleta diante das descobertas universais. Deu-se, então, um processo de atualização via jornalismo literário, que naquele momento histórico era o meio de comunicação de massa mais eficiente. $\mathrm{O}$ criador desse encarte, Haroldo Maranhão, ${ }^{5}$ proporcionou as condições necessárias para começar um processo de formação que resultaria em nomes como Mário Faustino, Benedito Nunes e Paulo Plínio Abreu. Este último teve papel fundamental dentro do Grupo dos Novos: foi o tradutor da famosa Duineser Elegien de Rilke, autor capital para a formação daqueles jovens escritores.

Rainer Maria Rilke (1975-1926), com as Duineser Elegien [Elegias de Duino], dispensa apresentações, mas cabe ressaltar que a sua recepção é lenta e gradual, passível ainda de intervenções, sobretudo no Brasil, onde tem a sua obra largamente traduzida, porém ainda 
pouco comentada. A fortuna de sua tradução vai do Oiapoque ao Chuí, se pensarmos na alusão geográfica extrema entre Norte e Sul, todavia ainda cheia de lacunas, que acreditamos ser realmente a distância (inclusive a geográfica) na comunicação entre esses polos formadores de culturas diversas (e não adversas) no horizonte das Ciências Humanas em nosso país continental.

Existem pelo menos duas traduções de Duineser Elegien publicadas na íntegra no Brasil. A mais famosa é a de Dora Ferreira da Silva. Contudo, há ainda a tradução do paraense Paulo Plínio Abreu, bem menos famosa, portanto, uma acanhada peça (quase artefato) arqueológica dentro de um livro intitulado simplesmente Poesia, publicado pela editora da Universidade Federal do Pará (UFPA), em 1978. Trata-se do único livro de Paulo Plínio Abreu, que morreu em 1959 e teve intensa participação na vida cultural da cidade de Belém, principalmente na época do Suplemento "Arte-literatura" do Jornal A Folha do Norte, organizado e editado postumamente por seu amigo e principal incentivador, Francisco Paulo Mendes. ${ }^{6}$ Nele, estão os poemas publicados nas revistas e jornais de Belém, além das Elegias de Duino, que também, a exemplo da tradução de Dora Ferreira da Silva, é bilíngue e comentada, elegia por elegia, por Paulo Plínio Abreu, que as verteu para o português em parceria com o antropólogo alemão Peter Paul Hilbert. Na verdade, pouco se sabe sobre a vida de Paulo Plínio Abreu, ${ }^{7}$ apenas algumas informações dadas por seu amigo F. Paulo Mendes.

Mas podemos afirmar que o referido poeta e tradutor paraense morreu em 1959; e a primeira tradução de Duineser Elegien na íntegra para língua portuguesa ocorreria em Portugal somente em 1969, ${ }^{8}$ por Paulo Quintela, e no Brasil, em 1972, por Dora Ferreira da Silva. Diante disso, acreditamos que, pelas evidências até aqui levantadas, a tradução de Paulo Plínio Abreu possa ser pioneira em língua portuguesa, não apenas no Brasil, mas no mundo. Não acreditamos que o argumento acima queira desqualificar as outras traduções de Duineser Elegien para a língua portuguesa, e sim acentuar a relevância desse tema para nós: trazer ao leitor brasileiro uma informação adicional, que pensamos ser relevante para um melhor entendimento do processo de recepção de Rilke no Brasil, através dessa tradução como mecanismo formador de nomes como Benedito Nunes, Mário Faustino, Haroldo Maranhão, Max Martins, Ruy Barata, Paulo Plínio Abreu e por que não dizer, Peter Paul Hilbert. Com efeito, vemos na referida tradução pliniana uma tarefa, sem a qual não seria menos difícil o vigor universalizante, que caracterizou todo o Grupo dos Novos. ${ }^{9}$ Figura-chave nesse contexto é Francisco Paulo Mendes: professor, ensaísta, pedagogo à moda antiga, mentor intelectual dessa geração, como assim entendeu Benedito Nunes. ${ }^{10}$ Escreveu, em 1944, a tese Raízes do 
Romantismo: ensaio sobre as origens espirituais e intelectuais do movimento romântico, que se tornaria livro somente em 1999, dias depois de sua morte (seria uma homenagem), às vésperas de completar 90 anos. Sobre esse ensaio, Benedito Nunes (1999), no Prefácio, que chamou de "Comentário da tese", diz:

\begin{abstract}
Mais do que acerca da origem da escola romântica, as Raízes do Romantismo nos instruem sobre a pré-formação filosófica do romantismo, com Locke e Rousseau; e nos ensinam com Schiller e Goethe, que, além de escola da natureza, a romântica o foi do depuramento da subjetividade e do lirismo. E por ter sido isso tudo, externando numa prolífica visão de mundo, que se estendeu à poesia simbolista, o romantismo se confunde com o espírito moderno. Enquanto esse espírito moderno subsistir, continuaremos sendo românticos (NUNES, 1999, p. 5-4).
\end{abstract}

O que nos chama a atenção nesse fragmento do "Comentário" são, além é claro de sua reflexão atualizadíssima, as expressões nos instruem e nos ensinam para salientar o caráter eminentemente "pedagógico" que Francisco Paulo Mendes exerceu sobre essa geração de escritores. Sua afinidade com o movimento romântico planta uma semente que brotaria no fazer literário desses literatos, que será expresso por meio da crítica e da poesia, confundidas muitas vezes com a tradução, como foi o caso de Duineser Elegien. Dessa forma, 36 percebemos, nessa geração de escritores, um profundo espírito de pesquisa. Uma inquietação típica dos Frühromantiker de se lançar ao desconhecido ${ }^{11}$ e ao estrangeiro. O projeto de Paulo Mendes era fazer uma atualização da literatura paraense e o seu modelo foi de fato o Romantismo e todo o seu desdobramento crítico e poético na sua contemporaneidade. A obra de Rilke, no nosso entender, era a que melhor traduziria o ambiente romântico de pensamento. O escritor tcheco foi declaradamente o seu predileto modelo de impecável forma e lirismo, motivo pelo qual foi o principal entusiasta da tradução das mais famosas elegias rilkeanas por Paulo Plínio Abreu e Paul Hilbert, por ver em Duineser Elegien um Vorbild [modelo] de atualização literária na Amazônia.

A nossa reflexão sobre esse fenômeno parte da necessidade de fornecermos informações relevantes, considerando que as condições de produção cultural, às quais estão submetidos os escritores, são muitas vezes motivo para o seu destino malogrado dentro de um historicismo segregador (BENJAMIN, 1998). Acreditamos que o ostracismo dessa tradução se deve a essa constatação, pois a lógica instrumental no uso da linguagem linear optou por contar a história como melhor lhe conviesse, criando uma tradição conformada, legitimada pelo progresso de nossa história literária. Todavia, a reflexão que punge nesse momento vai em direção ao resgate de documentos memorialísticos, que nos auxiliam a creditar novos rumos à história literária nacional, pois “em cada época, é preciso arrancar a tradição ao 
conformismo, que quer apoderar-se dela" (BENJAMIN, 1998, p. 224), e isso não deixa de ser também uma tarefa política.

Benjamin nos deixou esse legado como exemplo que ora tomamos como ferramenta. Pensamos que a relação tradutora operada por um intercâmbio transnacional ajudou a romper o isolamento em que se encontrava a geração intelectual paraense pós-1930, como vimos no depoimento de Paulo Plínio Abreu em entrevista dada ao Suplemento em 1947, respondendo à questão: “Que pensa a chamada 'geração moderna' de nosso Estado"?, da enquete "Posição e destino da literatura paraense".

Geração [do Grupo dos Novos] que conseguiu se libertar das fórmulas e preconceitos anacrônicos e procura viver no nível das questões universais. Que se libertou de regionalismo de toda espécie e que por isso mesmo que [sic] não se pode dizer dela que é "do nosso Estado". Só a insignificante geração literária que nos precedeu é que o era, e disso naturalmente se orgulhava (ABREU, 1947, p. 3).

O posicionamento vigoroso desse depoimento demonstra uma contestação à geração literária anterior conhecida por "Geração do peixe-frito", ${ }^{12}$ que tinha como proposta uma aversão aos ideais modernistas de 22 , demonstrando uma conduta conservadora vinculada à influência parnasiana. Percebemos que há em Paulo Plínio Abreu um esforço para atualizar a literatura de seu Estado, utilizando para isso a reflexão sobre o passado que não possibilitou o avanço dessa expressão. O seu conceito de "Novo" era genuíno, pois carregava em si o peso da atualização. Ele sabia que era uma proposta ousada. Por isso, todos apoiaram e colaboraram intensamente no Suplemento Arte-literatura do Jornal A folha do Norte. Souberam tirar proveito das ferramentas do seu momento histórico, que foi o momento em que a crítica nacional se desenvolveu eminentemente por meio de jornais e dos suplementos dominicais. Era um momento de puro entusiasmo, como percebemos no tom enérgico de Benedito Nunes:

Mais moderno do que modernista, este antiprovinciano tabloide dominical instrumentou, difundindo tudo o que de melhor e mais novo se fazia na literatura e na arte do país e do estrangeiro, o esforço de atualização que cada qual começara a empreender por conta própria. E golpeou o isolamento que ilhava a produção local (NUNES, 1992, p. 18).

Contudo, voltando ao depoimento no referido Suplemento por Paulo Plínio Abreu, é impressionante a sua consciência histórica que ajuíza bem o seu entendimento sobre o conceito de "geração literária" e a sua tarefa de atualização:

Creio que todas as gerações estão mais ou menos condenadas a um irremediável fracasso. Isso porque nenhuma geração conseguirá realizar ou traduzir integralmente 
a sua "mensagem". Todas as gerações necessariamente fracassarão. Todavia o valor de uma geração diante de si mesma e para as gerações que vierem depois não está na dependência desse fracasso que é inerente à essência mesma da sua condição temporal. Seu valor se medirá sempre pelo que há de eternamente novo na sua mensagem, pela reabilitação da literatura como forma autêntica de conhecimento, pela revalidação do mundo poético dentro de um mundo que tende a suprimi-lo. Nisto consiste a dignidade e o heroísmo de uma geração (ABREU, 1947, p. 38).

Dessa forma, diremos que Paulo Plínio Abreu exerceu um ato crítico por meio de uma tradução pioneira de um dos textos poéticos mais complexos da língua alemã, e esse legado foi salutar para a sua geração e para as gerações subsequentes. A sua capacidade de atingir lugares ermos e sombrios na sua inexpressiva aparência o fez questionar profundamente a linguagem. Isso o leva a traduzir, a fazer a ponte entre mundos [Über-setzungen], a pular sobre abismos sombrios da mente celestial de Rainer Maria Rilke, traduzindo a sua mensagem para aquela geração sedenta pelo novo, sabendo que "a luta não é/ com o anjo/ mas com o verbo/ que dissolve em poesia" (ABREU, 2008, p. 92), pois tinha certeza da grandeza do seu gesto: o Dichten [poetar], que quebra a hierarquia entre crítica e obra; entre original e tradução.

\section{A BILDUNG COMO FORMAÇÃO E SUA RELAÇÃO COM A TRADUÇÃO}

Surge aqui uma questão intercultural envolvendo essa tradução como um leitmotiv que atuará como ponte equânime entre a Amazônia e a Alemanha a partir dessa relação peculiar. Dessa maneira, dialogamos com as reflexões sobre a tradução como relação, a partir de $A$ prova do estrangeiro, de Antoine Berman (1942-1991), sobretudo no tocante à sua abordagem do conceito alemão de Bildung. Berman faz uma análise criteriosa do conceito de Bildung dentro da cultura alemã, tomando como ponto de partida a unificação linguística operada com a tradução da Bíblia para o alemão em 1534, principiando o Hochdeutsch [alemão padrão].

Contudo, a sua ênfase recairá sobre o final do século XVIII, no qual esse conceito terá repercussões diversas, inaugurando o capítulo da seguinte maneira:

O conceito de Bildung é um dos conceitos centrais da cultura alemã no final do século 18. É encontrado em toda parte: em Herder, em Goethe e Schiller, nos românticos, em Hegel, Fichte, etc. Bildung significa geralmente "cultura" e pode ser considerada como a variante erudita da palavra Kultur, de origem latina. Mas, para a família lexical à qual pertence, esse termo significa muito mais e se aplica a muitos outros registros: assim, pode-se falar da Bildung de uma obra de arte, de seu grau de "formação". Da mesma maneira, Bildung tem uma fortíssima conotação pedagógica e educativa: o processo de formação (BERMAN, 2002, p. 79).

Um ponto importante na sua articulação será pensar a Bildung com a sua conotação pedagógica. Nesse sentido, verificamos que o radical Bild [forma] é uma palavra-chave para a 
sua compreensão, pois a "formação" [Bildung] seria uma necessidade de ordenamento ideal da linguagem especulativa com ferramentas sistemáticas; notadamente em Herder, Goethe, Hegel e os românticos. Vemos um esforço em criar imagens orgânicas para reforçar a ideia de inexorabilidade: "a criança que deve se tornar homem, a virgem que deve se tornar mulher, o botão que deve se tornar flor, depois fruto" (BERMAN, 2002, p. 80). Resumindo, a Bildung [formação] é um processo para se chegar à Bild [forma] final, identitária, que possa representar todo um ideal, de indivíduo, de povo, de nação, de língua, de literatura e de obra de arte em geral.

O procedimento analítico de Berman será o de observar o potencial desse conceito, a partir do qual o jogo, ou o movimento dialético que ele representa, depende da "experiência" do "mesmo" em direção ao "outro", alcançando sua "formação", que, através da Reisebildung [viagem de formação] do "mesmo", torna-se "outro"; em uma palavra: a "experiência concluída é o tornar-se-si (eu do eu) do outro e o tornar-se-outro do mesmo" (BERMAN, 2002, p. 82). É uma consciência plena da "alteridade do mundo", haja vista que a

prova da alteridade, formação de si pela prova da alteridade, a experiência deve finalmente acontecer como reunião, identidade, unidade, momento supremo mesmo que demorado, pois a verdade dessa prova se situa em algum lugar entre o seu encerramento e a sua infinitude (BERMAN, 2002, p. 82).

É sabido que a fronteira nacional da Amazônia está aberta há bastante tempo às pesquisas em ciências naturais e humanas internacionais, mantendo um fluxo intenso de produções e cooperações científicas com grandes centros de pesquisas da Europa e dos Estados Unidos. Um sintoma desse processo é o prestígio que adquiriu o Museu Emílio Goeldi dentro e fora do Brasil, mantendo um periódico científico há mais de 100 anos: o Boletim do Museu Paraense Emílio Goeldi: Ciências Humanas e Naturais. A movimentação intensa de pesquisadores estrangeiros nesse centro de pesquisa nos chama a atenção, sobretudo pela grande participação de cientistas alemães que por lá passaram e que continua a acontecer até hoje. Então podemos crer que o processo de formação dessa relação científica entre a Amazônia e o mundo já tenha a sua forma definida. Foi o que buscou fazer a geração do Grupo dos Novos, que se comunicou com o mundo por meio do jornal A Folha do Norte. Acreditamos também que outras áreas do saber humano tenham contribuído para essa conquista literária. Nesse sentido, refletimos sobre o papel exercido pelo periódico Boletim do Museu Goeldi como veículo de difusão. Referimo-nos aqui a uma passagem da biografia escrita por Klaus Hilbert, professor de Arqueologia na PUC do Rio Grande do Sul, sobre o seu pai, o antropólogo Peter Paul Hilbert, intitulada Uma biografia de Peter Paul Hilbert: a 
história de quem partiu para ver a Amazônia, não por acaso publicada no referido Boletim. Nela, Klaus Hilbert afirma que Peter Paul, quando questionado sobre o porquê de vir para o Brasil, dizia que: "Queria ver o Amazonas, o Xingu e o Museu Goeldi” (HILBERT, 2009, p. 141). Certamente o Hilbert pai já conhecia o referido Museu paraense, ainda na Alemanha pré-Segunda Guerra Mundial. Paul Hilbert relatou que na casa de um amigo e professor na Universidade de Humboldt "pela primeira vez viu um exemplar do Museu Paraense Emílio Goeldi” (HILBERT, 2009, p. 38). Descobrimos também que Paul Hilbert era, antes de chegar à Amazônia, um desenhista e ficcionista, além de ativista cultural, com larga experiência como etnólogo na África. Serviu na Segunda Guerra Mundial, e três anos depois desta, embarcou rumo ao Brasil.

Em uma resenha recente publicada no boletim paraense por Sebastian Drude ${ }^{13}$ sobre o livro de Michael Kraus, intitulado em alemão como Bildungsbürger im Urwald: Die Deutsche ethnologische Amazonienforschung (1884-1929), ${ }^{14}$ livro que teve origem a partir de sua tese de doutorado defendida em Marburg em 2002, ainda sem tradução para o português, Drude ensaia traduzi-la como Burgueses de formação na selva: a pesquisa etnológica alemã na 40 Amazônia (1884-929). Esse autor comenta que hoje no Brasil já estão maduras as pesquisas científicas sobre a população nativa, suas culturas e línguas, em particular na Amazônia brasileira. Foi inevitável tocar em nomes de alemães amazonistas como o de Karl von den Stein, Paul Ehrenreich, Konrad T. Preuss, Max Schmidt, Fritz Krause e Theodor KochGrünberg, que tentaram dar respostas às questões de seu tempo. É claro que não passou despercebida a enorme lacuna deixada por Kraus, ao deixar de fora de suas apreciações o pesquisador Kurt Nimuendajú (1883-1945), que muito contribuiu para a história da antropologia brasileira. Eram "em geral, pesquisadores humanistas e críticos do etnocentrismo e das crenças progressistas de sua época; e como livres-pensadores e, em vários aspectos, céticos das teorias universalistas" (DRUDE, 2010, p. 189), enfim, “[esses pesquisadores] estavam preocupados mais em contribuir para a construção de conhecimento universal sobre a diversidade cultural ainda existente, do que com interesses nacionais e imperialistas, econômicos ou missionários" (DRUDE, 2010, p. 189) comenta o resenhador, lamentando o fato de que hoje algumas gralhas do passado ainda persistem:

Lamentavelmente, preconceitos contra pesquisadores do primeiro mundo retornam, hoje, por exemplo, sob o rótulo de "combate à biopirataria", no discurso nacionalista e também no discurso anti-imperialista e antiglobalização, supostamente progressista, colocando sob suspeita todo tipo de cooperação internacional. (DRUDE, 2010, 189). 
É importante notar que a pesquisa de Kraus vai somente até 1929, como bem percebe Drude, vinculando a diminuição nas excursões de alemães na Amazônia ao baixo financiamento à pesquisa no período entreguerras, fazendo com que houvesse uma diminuição expressiva no fluxo da pesquisa em etnologia na Alemanha, sentida até hoje como quase inexistente nas suas universidades, mesmo que seu legado ainda seja marca obrigatória nas universidades do Brasil e dos Estados Unidos.

Acreditamos que essa desconfiança para com o estrangeiro é própria da relação entre o "mesmo" e o "outro", que a Bildung romântica visa desconstruir, acabando com os isolamentos construídos pelo medo, ocasionados pela não compreensão das forças conflitantes, expressas nos conceitos de Treue [fidelidade] e Erweiterung [ampliação] (BERMAN, 2002). Contudo, percebemos um exemplo radical da capacidade de relacionamento entre culturas distintas e traumatizadas pela barbárie humana na amizade entre o alemão Peter Paul Hilbert e o israelense Sam Zebba, na ocasião da gravação de seu "Uirapuru"15 em plena Amazônia brasileira na década de 1960.

Já sabemos que Peter Paul Hilbert foi o grande colaborador de Paulo Plínio Abreu na tradução de Duineser Elegien na Amazônia nos anos 1950. A teia de relação que vincula esses dois homens é a busca pelo "novo". Um complemento generalizado de vida e obra, em uma palavra: momento crítico. Paul Hilbert veio "ver a Amazônia” possivelmente para ver outra imagem além daquela de catástrofes de seu continente pós-Segunda Guerra, e Paulo Plínio Abreu buscava fugir do isolamento, primeiro interior, e depois do ideológico, imerso em conformismo e resignação de uma geração de intelectuais paraenses anterior à sua.

A amizade começou quando Paulo Plínio trabalhava como bibliotecário e tradutor no antigo Centro Agronômico do Norte, vinculado ao Museu Emílio Goeldi, em cujo sítio morava com a família. Possivelmente, nesse ambiente, conheceu, em 1948, o recém-chegado antropólogo alemão Peter Paul, apresentando-o logo em seguida ao restante do Grupo dos Novos. Peter Paul logo se aclimatou, mostrando os seus dotes com a escrita e com o desenho através de artigos e vinhetas das capas nas três edições da revista Norte, editada em 1950 por Benedito Nunes, na qual publicou também o artigo chamado “O que é o Kitsch”. Quando ele chegou à Amazônia, já havia publicado dois livros: Der Fluss ohne Ende, em 1938; Jan aus dem Busch, em 1943; depois da experiência na Amazônia, escreveu Zoo im ersten Stock, em 1964; Der Diamantenpfad, em 1965, Sohn der Wassermutter, em 1965; e Um rio para o El Dorado, em parceria com o seu filho Klaus Hilbert, publicado em 2005; além, é claro, da 
tradução compartilhada de Duineser Elegien, publicada, como já dissemos, em 1978 no livro Poesia.

Acreditamos que Duineser Elegien de Rainer Maria Rilke mediou a relação entre esses dois escritores, impactando sobremaneira as suas produções literárias; além disso, foi decisiva na formação do Grupo dos Novos. Refiro-me ao seu Zeitgeist [clima] e seu ambiente de produção histórica, com trocas simbólicas para ambos os lados, formando, ao mesmo tempo, um "uno" identitário de uma época, como uma "forma" influenciadora para as gerações subsequentes. É a consciência de que a vida é uma escrita infinita, traduzida muitas vezes em arte, quando as grandes obras literárias são médiuns que refletem as afinidades profundamente íntimas entre as coisas, traduzíveis apenas no contato e na experiência transformadora do agora. 


\section{REFERÊNCIAS BIBLIOGRÁFICAS}

ABREU, Paulo Plínio. Poesia. Prefácio e notas de Francisco Paulo Mendes. 2. ed. Belém: EDUFPA, 2008.

. Resposta à enquete: posição e destino da literatura paraense. Folha do Norte, Belém, 14 dez. 1947. Suplemento Arte Literatura, p. 3.

BENJAMIN, Walter. Obras escolhidas. 2. ed. Tradução de Sergio Paulo Rouanet. São Paulo: Brasiliense, 1986.

Escritos sobre mito e linguagem (1915-1921). Apresentação, notas e de organização de Jeanne Marie Gagnebin; tradução de Susana Kampf Lages e Ernani Chaves. São Paulo: Duas Cidades/Editora 34, 2011a.

Conceito de crítica de arte no Romantismo alemão. Tradução, prefácio e notas de Márcio Seligmann-Silva. 3. ed. São Paulo: Iluminuras: 2011b.

BERMAN. Antoine. A prova do estrangeiro. Tradução de Maria Emília Pereira Chanut. Bauru, São Paulo: Edusc, 2002.

DRUDE, Sebastian. Expedições alemãs que fundaram a etnologia na Amazônia. Boletim do Museu Paraense Emílio Goeldi: Ciências Humanas e Naturais, Belém, v. 5, n. 1, p. 187190, jan.-abr. 2010.

GAGNEBIN, J. M. Nas fontes paradoxais da crítica literária. In: Leituras de Walter Benjamin. 2. ed. São Paulo: Annablume, 2007.

HILBERT, Klaus. Uma biografia de Peter Paul Hilbert: a história de quem partiu para ver a Amazônia. Boletim do Museu Paraense Emílio Goeldi: Ciências Humanas e Naturais, Belém, v. 4, n. 1, p. 135-154, jan.-abr. 2009.

MAUÉS, Júlia. A modernidade literária no Estado do Pará. Belém: UNAMA, 2002.

MENDES, Francisco Paulo. As raízes do Romantismo. Belém: Editora UFPA, 1999.

NUNES, Benedito. O amigo Chico, fazedor de poetas. Benedito Nunes (Org.). Belém: SECULT, 2001.

SELIGMANN-SILVA, Márcio. Walter Benjamin. In: A atualidade de Walter Benjamin e Theodor. W. Adorno. 2. ed. Rio de Janeiro: Civilização Brasileira, 2010. O local da diferença. São Paulo: Editora 34, 2005.

ZEBBA, Zam. Making "Uirapuru": a musical quest in the Brazilian Rain Forest. Boletim do Museu Paraense Emílio Goeldi: Ciências Humanas e Naturais, Belém, v. 5, n. 1, p. 173184, jan.-abr. 2010.

\footnotetext{
${ }^{1}$ Currículo Lattes em: <http://lattes.cnpq.br/2507019514021007>.

${ }^{2}$ Currículo Lattes em: < http://lattes.cnpq.br/1487725776729109 >.

${ }^{3}$ Hoje jornal $O$ liberal, mas que na década de 1940 e 1950 foi Folha do Norte, um importante periódico local que fazia oposição política ao coronel Manoel Barata, Intendente de Getúlio Vargas no Pará.

${ }^{4}$ Suplemento dominical criado por Haroldo Maranhão que documentou, entre 1946 e 1951, a efervescência literária nacional e local, tornando-se o principal tabloide literário na Amazônia da época. Ver A modernidade literária no Estado do Pará: o Suplemento literário da Folha do Norte de Júlia Maués - Belém - UNAMA: 2002.
} 
${ }^{5}$ Premiado romancista paraense; participou do Grupo dos Novos; publicou 18 livros em vida e outros postumamente. Morreu no Rio de Janeiro em 2004.

${ }^{6}$ Depoimento de Benedito Nunes: "foi um fazedor de poetas: impulsionou Ruy Barata, descobriu Paulo Plinio Abreu e Mario Faustino. Todos lhe ouvíamos a opinião, confiávamos no seu bom gosto, seguíamos os seus juízos críticos. Quantos livros me emprestou, quantos livros me deu! Soube antes de mim, que eu não seria poeta; encaminhou-me para o ensaio e a crítica." Ver detalhes em NUNES, 2001.

${ }^{7}$ Em 1921, nasceu em Belém do Pará; em 1940, entra na faculdade de Direito; nesse ano publica "Suicídio", "A estranha mensagem" e "A aventura", na revista Terra Imatura; em 1941, é contratado como tradutor pelo Instituto Agronômico do Norte (vinculado ao Museu Goeldi); em 1950, começa a colaborar no suplemento da Folha do Norte; em 1952, viaja para o Rio de Janeiro para tratar dos assuntos do periódico de seu trabalho; no mesmo ano é aceito como sócio do Instituto de Antropologia e Etnologia do Pará; em 1954, é convidado para reger a disciplina Literatura Brasileira, na Faculdade de Letras da UFPA; em 1956, profere aula inaugural na mesma instituição; em 1958, chefia o Departamento de Letras Vernáculas e Clássicas até sua morte, em 1959, aos 38 anos.

8 Para maiores informações acessar o site oficial do Instituto Camões: <http://cvc.institutocamoes.pt/conhecer/bases-tematicas/figuras-da-cultura-portuguesa/1439-paulo-quintela.html>. Acesso em: 12 jul. 2012. Nele, encontraremos todas as datas das traduções feitas de Rilke por Paulo Quintela.

${ }^{9}$ Benedito Nunes define o Grupo dos Novos em uma nota da seguinte forma: "Quero referir-me ao Grupo [dos Novos] reunido em torno dele [Francisco Paulo Mendes] dentro ou fora do Café Central, na casa de Machado Coelho e alhures, de que faziam parte, além do próprio Machado Coelho, Ruy Barata, Paulo Plínio Abreu, Mario Faustino, Raymundo de Sousa Moura, Haroldo Maranhão, Max Martins, Cauby Cruz e o autor desta nota de depoimento", em Mendes, Raízes do Romantismo.

${ }^{10}$ Ver nota 3 deste artigo.

$44 \quad{ }^{11}$ A partir da década de 1950, esses intelectuais começam a viajar pelo mundo, para a Europa e Estados Unidos.

${ }^{12}$ Antiacadêmicos, eles se encontravam na "academia ao ar livre", na Feira do Ver-o-peso em Belém para comer peixe frito e discutir literatura. Era um geração bem heterogênea, de padrões parnasianos. Eram conservadores no duplo sentido de serem também preservadores, pois estavam envolvidos com a cultura popular, como foi o caso de Bruno de Menezes e Dalcídio Jurandir.

${ }^{13}$ Doutor em Linguística pela Frei Universität Berlin e pesquisador associado do Museu Paraense Emílio Goeldi.

${ }^{14}$ Ver Boletim Paraense Emílio Goeldi: Ciências Humanas, Belém, v. 5, n. 1, p. 187-190, jan-abr. 2010.

${ }^{15}$ Sam Zebba, então um estudante israelense de cinema na Universidade da Califórnia, em Los Angeles, partiu para filmar uma lenda indígena brasileira, fixada em música por Heitor Villa-Lobos (1887-1959). A filmagem foi feita entre os índios Urubú-Ka'apor, no Maranhão. Em Belém, capital do Pará, Peter Paul Hilbert (19141989), antropólogo alemão do Museu Paraense Emílio Goeldi, se juntou a ele em uma expedição aventurosa e criativa, culminando em um premiado documentário artístico e em uma amizade que durou toda a vida. 